\title{
Aplicação de nitrogênio no cultivo de milho, sob sistema plantio direto: efeitos na qualidade física do solo e características agronômicas
}

\section{Nitrogen application in the maize, under no tillage system: effects in the soil physical quality and agronomics characteristics}

\author{
Flávia Carvalho Silva ${ }^{1 *}$; Monica Martins da Silva ${ }^{2}$; Paulo Leonel Libadi ${ }^{3}$
}

\section{Resumo}

O presente trabalho foi desenvolvido em área experimental da ESALQ-USP, município de Piracicaba/ SP, em um solo de textura areno-argilosa e teve por objetivo avaliar a qualidade física do solo e características agronômicas do milho submetido a diferentes doses de nitrogênio $(\mathrm{N})$, sob sistema de plantio direto. $\mathrm{O}$ delineamento experimental foi em blocos casualizados com quatro tratamentos e quatro repetições. Os tratamentos constaram de doses de $\mathrm{N}$, na forma de sulfato de amônio $(0,60,120$ e $180 \mathrm{~kg} \mathrm{ha}^{-1} \mathrm{de} \mathrm{N}$ ), sendo $30 \mathrm{~kg} \mathrm{ha}^{-1}$ de $\mathrm{N}$ na semeadura e o restante em cobertura, no estádio de 6 a 8 folhas, aplicados no milho e 1 sucessão de cultura (aveia preta-milho-tremoço branco-milho). Foram avaliados após os cultivos, densidade, microporosidade, macroporosidade e porosidade total do solo, nas camadas de $0,05,0,15,0,25,0,35 \mathrm{~m}$; altura de plantas, números de grãos por fileira e número de fileira por espiga, massa da matéria seca das plantas e rendimento de grãos de milho. Pelos resultados obtidos, conclui-se que as propriedades físicas do solo apresentam tendências de mudança com as doses de $\mathrm{N}$ e com o decorrer do tempo, principalmente no que se refere à macro e microporosidade do solo, condicionadas pela alteração estrutural do solo.

Palavras-chave: Manejo do solo, sucessão de culturas, adubação, propriedades físicas

\begin{abstract}
This research was developed in the experimental area of ESALQ-USP, city of Piracicaba, state of Sao Paulo, in a soil of sandy-clay texture and aimed to evaluate the soil physical quality and maize agronomic characteristics with maize crop under different $\mathrm{N}$ doses and different tillage systems. The experimental design consisted of randomized blocks with four replicates. Treatments consisted of three nitrogen doses $(\mathrm{N})\left(60,120\right.$, and $\left.180 \mathrm{~kg} \mathrm{ha}^{-1}\right)$ and a control. The ammonium sulfate fertilizer was applied at $30 \mathrm{~kg} \mathrm{ha}^{-1} \mathrm{~N}$ during seeding, and the rest was applied as sidedressing when the plants had between six and eight leaves. Were determined the bulk density, microporosity, macroporosity and total porosity of soil, at depths of $0.05,0.15,0.25,0.35 \mathrm{~m}$, and the maize components yield. The soil physical properties tend to change over time and $\mathrm{N}$ levels, especially with regard to soil macroporosity and microporosity, conditioned by the structural change of the soil.
\end{abstract}

Key words: Soil management, crop succession, fertilization, soil physical properties

\footnotetext{
${ }^{1}$ Eng $^{\mathrm{o}} \mathrm{Ag}^{\mathrm{o}}$, Prof. Dr. do Dept ${ }^{\mathrm{o}}$ de Agronomia, Universidade Estadual de Maringá, UEM, Maringá, PR. E-mail: flcarvalhoblg@ gmail.com

2 Eng $^{\circ}$ Agr $^{\circ}$, Pós Doutoranda, Dept ${ }^{\circ}$ Engenharia de Biossistemas, Escola Superior de Agricultura "Luiz de Queiroz", ESALQ, Piracicaba, SP. E-mail: monicamars@hotmail.com

3 Eng $^{\circ}$ Agr $^{\circ}$, Prof. Titular do Dept ${ }^{\circ}$ Engenharia de Biossistemas, ESALQ, Piracicaba, SP. E-mail: pllibard@usp.br

* Autor para correspondência
} 


\section{Introdução}

Devido ao uso intensivo, o solo tem-se degradado rapidamente, principalmente nos países tropicais, despertando nas últimas décadas, a sustentabilidade da exploração agrícola bem como a preocupação com a qualidade do solo. A produtividade de uma cultura, bem como sua alta rentabilidade, dependem fundamentalmente, da capacidade produtiva dos solos. Plantas que têm importância econômica, como o milho, por exemplo, podem ter sua produtividade elevada quando cultivado sob semeadura direta e rotação com plantas de cobertura. Assim, a associação de práticas agrícolas, como a calagem, a rotação de culturas e a adubação verde, objetivam proporcionar modificações nos teores de nutrientes no solo, na sua estrutura, na porosidade, na agregação, na densidade do solo, na infiltração e na disponibilidade de água, tendo em vista o adequado desenvolvimento radicular da cultura (SILVA; NADLER; KAY, 2001). O ideal seria o uso e o manejo do solo que estabelecessem uma associação conveniente desses atributos físicos, de modo que possibilitasse condições cada vez melhores para o crescimento e desenvolvimento vegetal, promovendo, conseqüentemente, menores perdas de solo e de água e, finalmente, maior produtividade associada à qualidade ambiental (SOUZA; ALVES, 2003).

No que se refere ao $\mathrm{N}$, este nutriente é o mais exigido pela cultura do milho e o seu suprimento inadequado é considerado um dos principais fatores limitantes ao crescimento e rendimento de grãos das culturas. Assim, plantas supridas adequadamente com $\mathrm{N}$, obtém um bom desenvolvimento radicular, podendo, no entanto, modificar as propriedades químicas e físicas do solo e consequentemente a sua qualidade.

$\mathrm{O}$ estoque de $\mathrm{N}$ total do solo pode ser recuperado no sistema plantio direto salientando-se, entretanto, a importância das espécies leguminosas com alta produção de resíduos vegetais nos sistemas de cultura e da adubação nitrogenada, que contribuem para a manutenção dos estoques de $\mathrm{N}$ total e de carbono orgânico total do solo, para a qualidade do solo e do ambiente e para a produtividade do milho (LOVATO et al., 2004).

No sistema plantio direto, o conceito de eficiência da fertilização nitrogenada é mais abrangente que no sistema convencional, uma vez que as doses de $\mathrm{N}$ são definidas de acordo com o sistema e com as culturas. Silva et al. (2006) enfatizou que a cultura antecessora tem efeito diferenciado sobre as características agronômicas e adubação do milho cultivado no sistema plantio direto e que na ausência de adubação nitrogenada, as maiores produtividades de milho são obtidas quando a cultura antecessora é ervilhaca peluda ou nabo forrageiro e as menores, quando a cultura antecessora é aveia preta.

Dessa forma, considerando a importância da adubação da cultura do milho, a recomendação de adubação nitrogenada no sul do Brasil é baseada no teor de matéria orgânica no solo, na expectativa de rendimento de grãos e no histórico de utilização da área (CFS-SC/RS, 1995). No entanto, existem vários outros fatores que poderão interferir na resposta do milho à aplicação de $\mathrm{N}$ em plantio direto que deveriam ser levados em consideração na recomendação de adubação deste nutriente. De acordo com Amado, Mielniczuk e Aita (2002) a proposta atual de recomendação de adubação nitrogenada deverá ser adaptada a situações em que outras fontes de $\mathrm{N}$ são utilizadas, tais como: culturas de cobertura de verão intercalares ao milho (mucuna, feijão-de-porco, crotalária e outras) e adubação orgânica (estercos de aves, suínos e bovinos). O tempo de utilização de culturas de cobertura e do sistema plantio direto (efeito residual) deverá ser considerado futuramente, visando à redução na dose de adubação mineral recomendada.

Dentro deste contexto e tendo em vista a falta de informação da influência da adubação nitrogenada em milho, nas características físicas do solo, este trabalho teve como objetivo avaliar a qualidade física do solo e características agronômicas do 
milho, em uma sucessão de culturas aveia pretamilho-tremoço branco-milho, sendo o milho submetido a diferentes doses de N, sob sistema de plantio direto.

\section{Material e Métodos}

O experimento foi conduzido, sob condições de campo, em área experimental da Escola Superior de Agricultura Luiz de Queiroz, Universidade de São Paulo. As coordenadas geográficas do local são $22^{\circ} 42^{\prime} 30^{\prime \prime}$ de latitude sul, 47³8'00" de longitude oeste e aproximadamente $546 \mathrm{~m}$ de altitude. Segundo a classificação internacional de Köppen, o clima da região é do tipo Cwa, denominado "tropical de altitude". Os dados pluviométricos durante a instalação do experimento estão representados na Figura 1 É um clima mesotérmico de inverno seco, em que a temperatura média do mês mais frio é inferior a $18^{\circ} \mathrm{C}$ e a do mês mais quente ultrapassa $22^{\circ} \mathrm{C}$. As médias anuais de temperatura, precipitação e umidade relativa são de $21,1^{\circ} \mathrm{C}, 1257$ $\mathrm{mm}$ e $74 \%$, respectivamente. A estação seca ocorre entre os meses de abril e setembro, sendo julho o mês mais seco. O mês mais chuvoso oscila entre janeiro e fevereiro e o total das chuvas do mês mais seco não ultrapassa $30 \mathrm{~mm}$. O solo do local é do tipo Latossolo Vermelho Amarelo (EMBRAPA, 1999), distrófico (Typic Haplustox) textura arenosa.

Figura 1. Dados pluviométricos durante os anos agrícolas 2004/2005 e 2005/2006.

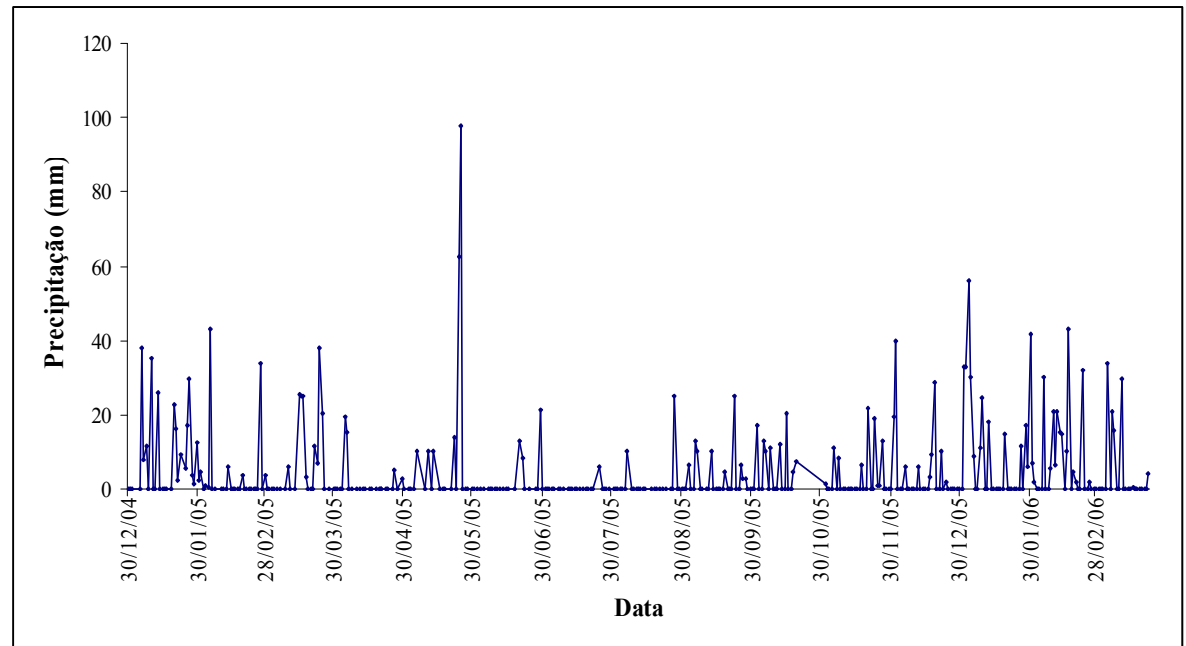

Fonte: Elaboração dos autores.

Por ocasião da instalação do experimento, foram coletadas amostras de solo das camadas $0,0-0,20,0,20-0,40,0,40-0,60$ e $0,60-0,80 \mathrm{~m}$ para a determinação das características físicas do perfil (Tabela 1).

O experimento foi instalado no ano de 2004, com a cultura do milho, após 1 ano da implantação do sistema plantio direto na área. O delineamento experimental foi em blocos aleatorizados com quatro tratamentos e quatro repetições. Os tratamentos constaram de doses de $\mathrm{N}$, na forma de sulfato de amônio (0, 60, 120 e $\left.180 \mathrm{~kg} \mathrm{ha}^{-1} \mathrm{de} \mathrm{N}\right)$, sendo $30 \mathrm{~kg}$ ha $^{-1}$ de $\mathrm{N}$ na semeadura e o restante em cobertura, no estádio de 6 a 8 folhas, aplicados no milho e 1 sucessão de cultura (aveia preta-milho-tremoço branco-milho). Cada parcela experimental consistiu de uma área de $36 \mathrm{~m}^{2}$ (5,0 x 7,2 m), com 9 linhas de milho espaçadas em $0,80 \mathrm{~m}$, sendo a distância entre parcelas de $2,0 \mathrm{~m}$. 
Silva, F. C.; Silva, M. M. da; Libadi, P. L.

Tabela 1. Densidade do solo (Ds), densidade das partículas (Dp), análise granulométrica e classe textural do solo, nas camadas 0,00-0,20, 0,20-0,40, 0,40-0,60 e 0,60-0,80 m, antes da instalação do experimento.

\begin{tabular}{|c|c|c|c|c|c|c|}
\hline Camadas (m) & $\begin{array}{c}\text { Ds } \\
\left(\mathrm{kg} \mathrm{m}^{-3}\right)\end{array}$ & $\begin{array}{c}\mathrm{Dp} \\
\left(\mathrm{kg} \mathrm{m}^{-3}\right)\end{array}$ & Areia & $\begin{array}{l}\text { Silte } \\
\mathrm{g} \mathrm{kg}^{-1}\end{array}$ & Argila & Classe textural \\
\hline $0,0-0,20$ & 1627 & 2754 & 840 & 20 & 140 & Areia franca \\
\hline $0,20-0,40$ & 1678 & 2760 & 800 & 20 & 180 & Franco-arenosa \\
\hline $0,40-0,60$ & 1675 & 2738 & 760 & 40 & 200 & Franco-argilo-arenosa \\
\hline $0,60-0,80$ & 1635 & 2693 & 760 & 40 & 200 & Franco-argilo-arenosa \\
\hline
\end{tabular}

Fonte: Elaboração dos autores.

O cultivar de milho utilizado nos anos agrícolas 2004/2005 e 2005/2006 foi o um híbrido simples, ciclo precoce, plantio normal, utilizado para produção de grãos e altamente resistente ao acamamento. As semeaduras foram realizadas manualmente em 02/12/2004 e 18/11/2005 para $1^{\circ}$ e $2^{\circ}$ cultivos, respectivamente. As sementes foram distribuídas com auxílio de uma régua, deixandose a cada $0,20 \mathrm{~m}$, duas sementes, desbastando-se para uma planta, duas semanas após a emergência, para obtenção de uma população final de aproximadamente 62.500 plantas por hectare, ou seja, 5 plantas por metro linear. A adubação básica (fosfatada e potássica), no sulco de semeadura, foi realizada em ambos os cultivos de milho na dose de $90 \mathrm{~kg} \mathrm{ha}^{-1}$ de $\mathrm{P}_{2} \mathrm{O}_{5}$ e $50 \mathrm{~kg} \mathrm{ha}^{-1}$ de $\mathrm{KCl}$ (RAIJ et al., 1997), na forma de superfosfato simples e cloreto de potássio, respectivamente e aplicados a $0,05 \mathrm{~m}$ ao lado e abaixo das sementes no momento da semeadura, para se evitar o contato direto com as sementes. As adubações nitrogenadas tiveram como fonte o sulfato de amônio e foram realizadas manualmente, no sulco de semeadura (adubação plantio) e incorporadas em sulco superficial a $0,20 \mathrm{~m}$ da linha da cultura (adubação de cobertura), quando as plantas de milho se encontravam no estádio de 6-8 folhas totalmente desdobradas. As plantas de milho atingiram o florescimento pleno em 10/02/2005 e 19/01/2006 e as colheitas ocorreram em 06/04/2005 e 22/03/2006, respectivamente para os $1^{\circ}$ e $2^{\circ}$ cultivos de milho. Após colheitas, realizou-se a trituração dos restos culturais com uma roçadeira lateral de 3 facas.
As plantas de cobertura (inverno/primavera) foram semeadas manualmente, em 29/07/2004 e 09/06/2005 com uma densidade de sementes de 60 $\mathrm{kg} \mathrm{ha}^{-1}$ e 33 sementes por $\mathrm{m}^{2}$ e espaçamento de 0,20 e $0,30 \mathrm{~m}$, respectivamente para a aveia e o tremoço branco. Na aveia preta, a adubação básica foi de $30 \mathrm{~kg} \mathrm{ha}^{-1}$ de $\mathrm{N}, 90 \mathrm{~kg} \mathrm{ha}{ }^{-1}$ de $\mathrm{P}_{2} \mathrm{O}_{5}$ e $50 \mathrm{~kg} \mathrm{ha}^{-1}$ de $\mathrm{K}_{2} \mathrm{O}$ (RAIJ et al., 1997) na forma de sulfato de amônio, superfosfato simples e cloreto de potássio, respectivamente, feita à lanço após a semeadura. No tremoço branco, a adubação básica foi de $40 \mathrm{~kg} \mathrm{ha}^{-1}$ de $\mathrm{P}_{2} \mathrm{O}_{5}$ e $30 \mathrm{~kg} \mathrm{ha}^{-1}$ de $\mathrm{K}_{2} \mathrm{O}$ (RAIJ et al., 1997) na forma de superfosfato simples e cloreto de potássio, respectivamente, feita a lanço após a semeadura. O manejo mecânico das plantas de cobertura foi feito, após a aplicação de herbicida, na época do florescimento pleno (28/10/2004 e 24/08/2005), respectivamente para aveia preta e tremoço branco, com uma roçadeira lateral de 3 facas.

No sulco de semeadura foi aplicado o Furadan (para controlar pragas do solo) na dose de $20 \mathrm{~kg}$ $\mathrm{ha}^{-1}$. Durante os cultivos de milho também foram controladas a lagarta do cartucho (Spodoptera frugiperda J.E. Smith), pulverizando lufenuron (match $300 \mathrm{ml} \mathrm{ha}^{-1}$ ) e zetacipermetrina (Mustang 350 EC $\left.60 \mathrm{ml} \mathrm{ha}^{-1}\right)$, e formigas, pulverizandose deltametrina (K-Otrine 2P $10 \mathrm{~g} /$ ninho). Para o controle de plantas daninhas foi utilizado o herbicida em pós-emergência glifosato, na dose de $2400 \mathrm{~g} \mathrm{ha}^{-1}$ do i.a.

As avaliações realizadas foram: propriedades físicas do solo: após o manejo da aveia preta em 2004 e do tremoço branco em 2005 e após a 
colheita do milho em 2005 e 2006, amostragens de solos foram feitas nas camadas de 0,00-0,10, 0,100,20, 0,20-0,30, 0,30-0,40 m para determinação da densidade do solo pelo método do anel volumétrico, microporosidade, pelo método da mesa de tensão (EMBRAPA, 1997), porosidade total, determinada pela umidade de saturação ou porcentagem de saturação em volume e macroporosidade, pela diferença de porosidade total e microporosidade (EMBRAPA, 1997); características agronômicas do milho e massa da matéria seca das plantas: para altura de plantas foram medidas, ao acaso, 10 plantas por parcela, medindo-se a distância entre o colo das plantas até a inserção da última folha; o número de fileiras por espiga e o número de grãos por fileira foi obtido pela contagem de fileiras de 10 espigas colhidas em plantas de três linhas internas das parcelas, separadas aleatoriamente, antes da trilhagem dos grãos; a massa de 100 grãos foi obtida pela pesagem de duas amostras de 100 grãos e contados manualmente; a massa da matéria seca das plantas foi feita por ocasião da colheita, no final do ciclo das culturas, quando foram coletadas quatro plantas por parcela, as quais foram secas e pesadas; para determinar o rendimento de grãos foram colhidas espigas de três linhas internas das parcelas. Os grãos foram trilhados e pesados e, então, transformados em $\mathrm{kg} \mathrm{ha}^{-1}$ (13\% de umidade); massa da matéria seca da aveia preta: coletaram-se as plantas na época do florescimento pleno, em uma área útil de 1,0 $\mathrm{m}^{2}$ da parcela e, para o tremoço branco, coletaram-se 10 plantas por parcela e determinada a fitomassa seca em estufa com circulação forçada de ar a $60-70^{\circ} \mathrm{C}$, até a massa constante, em balança de precisão.
Os dados foram submetidos à análise de variância, comparação de médias pelo teste de Tukey $(p=0,05)$. Quando avaliados os efeitos de doses utilizou-se a regressão. O programa utilizado foi o SISVAR.

\section{Resultados e Discussão}

Os resultados do teste $\mathrm{F}$ e coeficiente de variação para a porosidade total (PT), macroporosidade, microporosidade e densidade do solo nas camadas de $0,00-0,10,0,10-020,0,20-0,30$ e $0,30-0,40 \mathrm{~m}$ estão apresentados na Tabela 2. Embora avaliados nos primeiros anos de implantação do SPD (a partir do $2^{\circ}$ ano) os resultados somente não foram significativos para a densidade do solo em nenhuma das camadas estudadas.

Os resultados significativos para a PT (Tabela 3) foram encontrados somente entre épocas e na camada de 0,00-0,10 m, onde verificou-se que a PT foi maior quando avaliada após o cultivo da aveia preta, diminuindo nas demais épocas de avaliação.

Nas demais camadas, a PT permaneceu praticamente constante, com uma moderada tendência de diminuição com o tempo, o que já era esperado nas camadas superficiais devido ao não revolvimento do solo no SPD: a falta de mobilização do solo diminui o volume do espaço poroso do solo (STONE; SILVEIRA, 2001; SECCO et al., 2005). Apesar de não ter sido observada diferença significativa entre as doses de N para a PT, percebese uma tendência de aumento da PT do solo com o aumento da dose de $\mathrm{N}$ na camada de 0,00-0,10 m, comportamento não observado nas demais camadas, as quais mantiveram certa constância de PT. 
Tabela 2. Teste $\mathrm{F}$ e coeficiente de variação (CV) para diferentes doses de N, épocas e interação épocas x doses, referentes a porosidade total, macroporosidade, microporosidade e densidade, nas camadas $0,00-0,10,0,10-0,20$, 0,20-0,30 e 0,30-0,40 $\mathrm{m}$ do solo.

\begin{tabular}{|c|c|c|c|c|}
\hline \multirow{2}{*}{ Causas da variação } & \multicolumn{4}{|c|}{ Camadas (m) } \\
\hline & $0,00-0,10$ & $0,10-0,20$ & $0,20-0,30$ & $0,30-0,35$ \\
\hline & \multicolumn{4}{|c|}{ Porosidade total } \\
\hline Dose (D) & $1,99^{\mathrm{ns}}$ & $0,03^{\mathrm{ns}}$ & $2,13^{\mathrm{ns}}$ & $1,26^{\mathrm{ns}}$ \\
\hline Época (E) & $58,14 * *$ & $0,83^{\mathrm{ns}}$ & $0,96^{\mathrm{ns}}$ & $2,41^{\mathrm{ns}}$ \\
\hline $\mathrm{E}^{*} \mathrm{D}$ & $1,42^{\mathrm{ns}}$ & $0,02^{\text {ns }}$ & $0,16^{\mathrm{ns}}$ & $0,47^{\mathrm{ns}}$ \\
\hline \multirow[t]{2}{*}{ CV $(\%)$} & 2,77 & 3,08 & 3,24 & 3,84 \\
\hline & \multicolumn{4}{|c|}{ Macroporosidade } \\
\hline Dose (D) & $122,32 * *$ & $7,41 *$ & $14,59 * *$ & $10,20 * *$ \\
\hline Época (E) & $1011,99 * *$ & $6,00^{*}$ & $14,76^{* *}$ & $79,44 * *$ \\
\hline $\mathrm{E}^{*} \mathrm{D}$ & $39,63 * *$ & $0,45^{\mathrm{ns}}$ & $0,46^{\mathrm{ns}}$ & $3,39 *$ \\
\hline \multirow[t]{2}{*}{ CV $(\%)$} & 4,55 & 10,99 & 8,74 & 5,5 \\
\hline & \multicolumn{4}{|c|}{ Microporosidade } \\
\hline Dose (D) & $4,11^{*}$ & $9,37 * *$ & $16,45^{* *}$ & $0,26^{\mathrm{ns}}$ \\
\hline Época (E) & $8,86^{* *}$ & $19,84 * *$ & $1,75^{\text {ns }}$ & $0,30^{\mathrm{ns}}$ \\
\hline $\mathrm{E}^{*} \mathrm{D}$ & $0,77^{\mathrm{ns}}$ & $0,70^{\text {ns }}$ & $0,21^{\mathrm{ns}}$ & $0,12^{\mathrm{ns}}$ \\
\hline \multirow[t]{2}{*}{ CV (\%) } & 4,12 & 2,17 & 3,17 & 4,45 \\
\hline & \multicolumn{4}{|c|}{ Densidade do solo } \\
\hline Dose (D) & $0,98^{\mathrm{ns}}$ & $0,04^{\mathrm{ns}}$ & $0,80^{\mathrm{ns}}$ & $0,58^{\mathrm{ns}}$ \\
\hline Época (E) & $1,31^{\mathrm{ns}}$ & $2,74^{\mathrm{ns}}$ & $0,70^{\text {ns }}$ & $1,71^{\mathrm{ns}}$ \\
\hline $\mathrm{E}^{*} \mathrm{D}$ & $0,27^{\mathrm{ns}}$ & $0,36^{\mathrm{ns}}$ & $0,48^{\mathrm{ns}}$ & $0,57^{\mathrm{ns}}$ \\
\hline CV (\%) & 4,49 & 4,06 & 4,68 & 4,11 \\
\hline
\end{tabular}

ns: não significativo; * significativo a $1 \%$; ** significativo a $5 \%$ de probabilidade pelo teste de Tukey.

Fonte: Elaboração dos autores.

Tabela 3. Teste de Tukey para épocas de avaliação: (1) após cultivo de aveia preta , (2) após $1^{\circ}$ cultivo de milho; (3) após cultivo de tremoço branco; (4) após $2^{\circ}$ cultivo de milho, referentes à porosidade total das camadas de $0,00-0,10$, 0,10-0,20, 0,20-0,30 e 0,30-0,40 m de solo.

\begin{tabular}{cccccc}
\hline & \multicolumn{4}{c}{ Porosidade total (\%) } \\
\cline { 3 - 5 } & & \multicolumn{4}{c}{ Camadas (m) } \\
\cline { 2 - 5 } & 1 & $4,00-0,10$ & $0,10-, 0,20$ & $0,20-0,30$ & $0,30-0,40$ \\
\hline \multirow{3}{*}{ Época } & $21,98 \mathrm{a}$ & $34,56 \mathrm{a}$ & $32,46 \mathrm{a}$ & $32,30 \mathrm{a}$ \\
& 2 & $36,19 \mathrm{~b}$ & $35,18 \mathrm{a}$ & $31,69 \mathrm{a}$ & $30,97 \mathrm{a}$ \\
& 3 & $36,17 \mathrm{~b}$ & $35,33 \mathrm{a}$ & $31,90 \mathrm{a}$ & $30,95 \mathrm{a}$ \\
& 4 & $36,69 \mathrm{~b}$ & $35,22 \mathrm{a}$ & $31,72 \mathrm{a}$ & $31,02 \mathrm{a}$ \\
\hline
\end{tabular}

Médias na mesma coluna, seguidas por letras comuns não diferem entre si em nível de significância de 5\% pelo teste de Tukey. Épocas: (1); (2).

Fonte: Elaboração dos autores.

Marinari et al. (2000) estudando a influência de fertilizantes minerais e orgânicos nas propriedades físicas e químicas do solo e Haiti et al. (2007) estudando as mudanças nas propriedades físicas e no carbono orgânico de um solo após 28 anos de manejo contínuo, observaram aumento na PT com a aplicação de fertilizante nitrogenado na camada de 0,0-0,15 m. De acordo com Lanzanova et al. (2007) 
a densidade e a PT são as propriedades físicas mais amplamente utilizadas na quantificação da qualidade física do solo, em pastagem sob pastejo, a qual é mais afetada nos primeiros $150 \mathrm{~mm}$ de profundidade.

Dessa forma, resultados aqui obtidos foram devidos, provavelmente, ao aumento da massa de matéria seca das plantas com o aumento da dose de $\mathrm{N}$ que levou a um maior desenvolvimento radicular com influência na PT, principalmente na menor camada.

O teste de Tukey e as regressões para épocas de avaliação e doses de $\mathrm{N}$ referentes à macroporosidade nas camadas 0,00-0,10, 0,10-020, 0,20-0,30 e 0,30-0,40 m constam na Tabela 4 . Os resultados obtidos mostraram significância para a interação entre épocas e doses nas camadas de 0,00-0,10 e 0,30-0,40 m (Tabela 5) sendo que, em ambas as camadas, se observa o mesmo comportamento, ou seja, diminuição da macroporosidade com a época de avaliação assim como observado para a PT. Devido o cultivo da aveia-preta, os valores foram sempre maiores, confirmando a influência positiva desta gramínea nas propriedades físicas do solo. No SPD, em geral, os solos apresentam, nas camadas superficiais, após três a quatro anos, menores valores de macroporosidade e PT quando comparado com o preparo convencional, decorrente, sobretudo, do arranjamento natural do solo quando não é mobilizado (VIEIRA; MUZZILI, 1984; CORREA, 1985; CASTRO, 1989). Stone e Silveira (2001) observaram após três e quatro anos de SPD, menores valores de macroporosidade e PT.

Tabela 4. Teste de Tukey para épocas de avaliação (1) Após cultivo de aveia preta; (2) Após $1^{\circ}$ cultivo de milho; (3) Após cultivo de tremoço branco; (4) Após $2^{\circ}$ cultivo de milho, referentes macroporosidade, nas camadas de $0,00-0,10$, 0,10-0,20, 0,20-0,30 e 0,30-0,40 m e regressões para doses de $\mathrm{N}$ nas camadas $0,10-0,20$ e $0,20-0,30 \mathrm{~m}$ de solo.

\begin{tabular}{lccccc}
\hline & \multicolumn{4}{c}{ Macroporosidade (\%) } \\
\cline { 3 - 5 } & & \multicolumn{4}{c}{ Camadas (m) } \\
\cline { 3 - 5 } & 1 & $0,00-0,10$ & $0,10-0,20$ & $0,20-0,30$ & $0,30-0,40$ \\
\hline \multirow{3}{*}{ Épocas } & 2 & $6,70 \mathrm{a}$ & $7,67 \mathrm{a}$ & $6,79 \mathrm{a}$ & $6,31 \mathrm{a}$ \\
& 3 & $5,33 \mathrm{a}$ & $6,88 \mathrm{a}$ & $6,03 \mathrm{a}$ & $4,68 \mathrm{a}$ \\
& 4 & $5,30 \mathrm{a}$ & $6,55 \mathrm{a}$ & $5,58 \mathrm{a}$ & $4,55 \mathrm{a}$ \\
\multirow{2}{*}{ Doses } & $\mathrm{n}$ & $6,14 \mathrm{a}$ & $5,15 \mathrm{a}$ & $4,51 \mathrm{a}$ \\
& & $\mathrm{n} . \mathrm{s}$ & $\mathrm{y}=0,0091 \mathrm{x}+5,996$ & $\mathrm{y}=0,0088 \mathrm{x}+5,094$ & n.s \\
\hline
\end{tabular}

Fonte: Elaboração dos autores.

Secco et al. (2005) obtiveram o mesmo comportamento para os valores de macroporosidade e PT, uma vez que nos tratamentos que sofreram menor mobilização do solo, nas três camadas e nos três anos avaliados, os valores foram inferiores em relação aos demais sistemas de manejo do solo. Em relação às doses de $\mathrm{N}$, a macroporosidade aumentou positivamente em todas as épocas avaliadas, apesar de na camada de 0,30-0,40 m ter ocorrido aumento significativo da macroporosidade somente na $1^{\text {a }}$ época avaliada (após cultivo da aveia preta) com valores absolutos notadamente crescentes, porém sem diferença estatística, nas demais épocas avaliadas. Isso pode ser resultado do maior desenvolvimento radicular das plantas quando se aplica o fertilizante nitrogenado. Esses resultados estão de acordo com Fernandes (2006) que estudando a dinâmica do $\mathrm{N}$ na cultura do milho em cultivo sucessivo com a aveia em SPD, obteve ajuste linear para a macroporosidade com as doses de N. Lange (2002) pelo contrário, ao estudar o efeito da palhada e $\mathrm{N}$ nas propriedades do solo e 
rendimento de milho em SPD no cerrado, concluiu que as propriedades físicas do solo não foram influenciadas pelas doses de $\mathrm{N}$ aplicadas.

$\mathrm{Na}$ Tabela 5, observa-se que os valores de macroporosidade nas camadas de 0,10-0,20 e 0,20-
0,30 m em função das doses de $\mathrm{N}$ ajustaram-se a funções lineares crescentes, ou seja, houve aumento desta característica do solo com o aumento da dose do fertilizante nitrogenado.

Tabela 5. Médias e teste de Tukey do desdobramento épocas dentro de doses de $\mathrm{N}$ referentes a macroporosidade do solo, nas camadas de 0,00-0,10 e 0,30-0,40 m.

\begin{tabular}{lcccc}
\hline \multirow{2}{*}{$\begin{array}{c}\text { Doses } \\
\left(\mathrm{kg} \mathrm{ha}^{-1}\right)\end{array}$} & \multicolumn{5}{c}{ Macroporosidade $(\%)$} \\
\cline { 2 - 5 } & \multicolumn{4}{c}{ Épocas } \\
\cline { 2 - 5 } 0 & \multicolumn{4}{c}{ Camada 0,05} \\
60 & $8,36 \mathrm{aB}$ & $5,04 \mathrm{bC}$ & $5,03 \mathrm{bB}$ & $5,02 \mathrm{bA}$ \\
120 & $15,09 \mathrm{aA}$ & $6,27 \mathrm{bB}$ & $5,20 \mathrm{cB}$ & $5,15 \mathrm{cA}$ \\
180 & $15,28 \mathrm{aA}$ & $6,54 \mathrm{bAB}$ & $5,44 \mathrm{cB}$ & $5,18 \mathrm{cA}$ \\
& $16,07 \mathrm{aA}$ & $7,46 \mathrm{bA}$ & $7,29 \mathrm{bA}$ & $5,87 \mathrm{cA}$ \\
0 & & \multicolumn{4}{c}{ Camada 0,35} & \\
60 & $5,09 \mathrm{aB}$ & $4,40 \mathrm{aA}$ & $4,38 \mathrm{aA}$ \\
120 & $6,48 \mathrm{aA}$ & $4,51 \mathrm{aA}$ & $4,45 \mathrm{bA}$ & $4,40 \mathrm{bA}$ \\
180 & $6,71 \mathrm{aA}$ & $4,58 \mathrm{bA}$ & $4,63 \mathrm{bA}$ & $4,56 \mathrm{bA}$ \\
\hline
\end{tabular}

Médias seguidas de letras minúsculas iguais na mesma linha e maiúsculas iguais na coluna, não diferem entre si em nível de

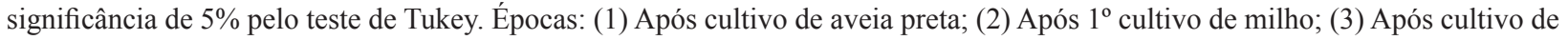
tremoço branco; (4) Após $2^{\circ}$ cultivo de milho.

Fonte: Elaboração dos autores.

Apesar disso, tal resultado pode ser atribuído à atividade radicular, ou seja, devido aos incrementos na massa de matéria seca, como já mencionado anteriormente para a PT. Observou-se ainda que, com exceção da $1^{\mathrm{a}}$ época de avaliação na camada de 0,00-0,10 m e nas doses de 60, 120 e $180 \mathrm{~kg} \mathrm{ha}^{-1}$, os valores de macroporosidade estão abaixo do limite crítico de aeração considerado impeditivo para o crescimento de raízes (10\%) (GRABLE; SIEMER, 1968). Segundo Giusquiani, et al. (1994) apud Marinari et al. (2000), a principal consideração a ser feita a respeito dos macroporos não é somente a sua forma, mas também a distribuição do seu tamanho, especialmente de poros contínuos e alongados, uma vez que eles são diretamente relacionados ao crescimento das plantas, isto é, por facilitar a penetração radicular e armazenagem de água e gases.
O teste de Tukey e regressões para épocas de avaliação e doses de $\mathrm{N}$ referentes à microporosidade nas camadas 0,00-0,10, 0,10-0,20, 0,20-0,30 e 0,30-0,40 m constam na Tabela 6. Apesar de não ter ocorrido diferença significativa para as épocas de avaliação, os resultados mostraram tendência de aumento com o tempo, concordando com Stone e Silveira (2001), os quais observaram maiores valores de microporosidade após três e quatro anos de adoção do SPD. Esses dados concordam com os de Fidalski et al. (2008),os quais constaram diferenças entre as camadas de solo $(\mathrm{p}<0,05)$, e foi observada menor densidade do solo e maior microporosidade e capacidade de armazenamento de água do solo na camada $0-75 \mathrm{~mm}$, em comparação à de 75-150 $\mathrm{mm}$ de profundidade. Esses resultados caracterizam o maior armazenamento de água na camada superficial, em razão dos maiores teores 
de C orgânico. Os resultados foram significativos para doses nas camadas de 0,00-0,10, 0,10-0,20 e 0,20-0,30 m (Tabela 7) os quais ajustaram-se a equações lineares sendo que, a microporosidade diminuiu com as doses de $\mathrm{N}$, estando de acordo com a macroporosidade que teve efeito inverso.

Tabela 6. Teste de Tukey para épocas de avaliação (1) Após cultivo de aveia preta; (2) Após $1^{\circ}$ cultivo de milho; (3) Após cultivo de tremoço branco; (4) Após $2^{\circ}$ cultivo de milho, referentes microporosidade, nas camadas de $0,00-0,10$, $0,10-0,20,0,20-0,30$ e $0,30-0,40 \mathrm{~m}$ e regressões para doses de $\mathrm{N}$ nas camadas $0,00-0,10,10-0,20$ e $0,20-0,30 \mathrm{~m}$ de solo.

\begin{tabular}{llcccc}
\hline & \multicolumn{4}{c}{ Microporosidade (\%) } \\
\cline { 3 - 5 } & 1 & $0,00-0,10$ & $0,10-0,20$ & $0,20-0,30$ & $0,30-0,40$ \\
\cline { 2 - 5 } & $28,28 \mathrm{a}$ & $26,89 \mathrm{a}$ & $25,68 \mathrm{a}$ & $25,99 \mathrm{a}$ \\
\multirow{3}{*}{ Épocanadas $(\mathrm{m})$} & $28,30 \mathrm{a}$ & $25,86 \mathrm{a}$ & $26,30 \mathrm{a}$ \\
& 2 & $29,86 \mathrm{a}$ & $28,78 \mathrm{a}$ & $26,12 \mathrm{a}$ & $26,40 \mathrm{a}$ \\
& 3 & $30,43 \mathrm{a}$ & $29,07 \mathrm{a}$ & $26,57 \mathrm{a}$ & $26,52 \mathrm{a}$ \\
\multirow{2}{*}{ Dose } & 4 & $31,38 \mathrm{a}$ & $\mathrm{y}=-0,0083 \mathrm{x}+29,00$ & $\mathrm{y}=-0,0112 \mathrm{x}+30,99$ & $\mathrm{~ns}$ \\
& & $\mathrm{y}=-0,0142 \mathrm{x}+27,34$ & $\left(\mathrm{R}^{2}=0,93\right)$ & $\left(\mathrm{R}^{2}=0,94\right)$ & \\
\hline
\end{tabular}

Fonte: Elaboração dos autores.

Tabela 7. Teste de Tukey para épocas de avaliação e doses de $\mathrm{N}$ referentes à densidade do solo nas camadas de 0,00 $0,10,0,10-0,20,0,20-0,30$ e $0,30-0,40 \mathrm{~m}$.

\begin{tabular}{llcccc}
\hline & & \multicolumn{4}{c}{ Densidade do solo $\left(\mathrm{kg} \mathrm{m}^{-3}\right)$} \\
\cline { 3 - 5 } & & $0,00-0,10$ & $0,10-0,20$ & $0,20-0,30$ & $0,30-0,40$ \\
\hline \multirow{3}{*}{ Épocamadas $(\mathrm{m})$} & $1710 \mathrm{a}$ & $1730 \mathrm{a}$ \\
& 1 & $1530 \mathrm{a}$ & $1620 \mathrm{a}$ & $1660 \mathrm{a}$ & $1720 \mathrm{a}$ \\
& 2 & $1570 \mathrm{a}$ & $1560 \mathrm{a}$ & $1660 \mathrm{a}$ & $1720 \mathrm{a}$ \\
& 3 & $1580 \mathrm{a}$ & $1540 \mathrm{a}$ & $1660 \mathrm{a}$ & $1660 \mathrm{a}$ \\
\multirow{2}{*}{ Doses } & 4 & $1600 \mathrm{a}$ & $1590 \mathrm{a}$ & 1690 & 1700 \\
ha $\left.^{-1}\right)$ & 0 & 1550 & 1580 & 1690 & 1740 \\
& 120 & 1600 & 1580 & 1640 & 1690 \\
& 180 & 1560 & 1570 & 1650 & 1720 \\
\hline
\end{tabular}

Épocas: (1) Após cultivo de aveia preta; (2) Após $1^{\circ}$ cultivo de milho; (3) Após cultivo de tremoço branco; (4) Após $2^{\circ}$ cultivo de milho.

Fonte: Elaboração dos autores.

O teste de Tukey para épocas de avaliação e doses de $\mathrm{N}$ referentes à densidade do solo nas camadas 0,00-0,10, 0,10-0,20, 0,20-0,30 e 0,30-0,40 m estão apresentados na Tabela 7 , onde verifica-se que não houve diferença significativa para épocas de avaliação e nem para doses de N.

$\mathrm{Na}$ camada de 0,00-0,10 m percebe-se uma moderada tendência de aumento da densidade do solo com o tempo de estudo e, nas demais camadas os valores permaneceram praticamente constantes, não indicando tendência de adensamento. Sarmento et al. (2008) verificaram maior densidade do solo na camada superficial, quando estudaram atributos químicos e físicos de um Argissolo cultivado com Panicum maximum Jacq., sob lotação rotacionada e adubado com nitrogênio. Contudo, mudanças 
imediatas e substanciais na camada superficial do solo durante sua adaptação ao manejo reduzido têm sido relatadas por vários pesquisadores (VOORHEES; LINDSTRON, 1984; CARTER, 1991; STONE; SILVEIRA, 2001; MUNKHOLM et al., 2003).

O aumento do conteúdo de matéria orgânica com o tempo nesse sistema, porém, pode reduzir a densidade do solo. Contudo percebe-se que as propriedades físicas do solo têm mudado paulatinamente com o tempo e com a aplicação do fertilizante nitrogenado, sendo interessante um estudo a longo prazo no SPD, para se obter resultados mais significativos e conclusivos. Kushwaha, Singh e Tripathi (2001); Silva, Nadler e Kay (2001); Dam et al. (2005) concluíram que as práticas de manejo tiveram um grande impacto na densidade do solo, sendo que os últimos autores observaram maior diferença na densidade do solo devido ao tipo de manejo adotado do que à presença de resíduos na superfície durante os 11 anos de estudos.

Para as características agronômicas do milho para as safras 2004/2005 e 2005/2006, observouse houve efeito das doses de $\mathrm{N}$ para todas as características estudadas, concordando com Costa et al. (2012) que estudando a adubação nitrogenada no consórcio de milho com duas espécies de braquiária em sistema plantio direto verificaram que a safra de 2009/2010, os componentes da produção e a produtividade de grãos apresentaram efeito das doses de N em cobertura. Segundo esses autores, os componentes número de fileiras, grãos por fileira e grãos por espiga, estão diretamente associados e apresentaram o mesmo comportamento linear crescente em função das doses de $\mathrm{N}$ em cobertura, o que mostra o papel fundamental deste nutriente para a formação dos grãos de milho na espiga.

A resposta do milho quanto à altura de plantas foi quadrática (Figura 2A) em ambas as safras. O tratamento que não se aplicou $\mathrm{N}$ apresentou a menor altura de plantas como já era esperado, demonstrando que essa característica depende de aplicação de N. Tozetti et al. (2004) avaliando progênies de milho na presença e ausência de adubo, verificaram que a adubação afeta diretamente a altura de plantas. Fernandes (2006) também verificou efeito das doses de $\mathrm{N}$ na altura de plantas de milho.

Para o número de grãos por fileira e comprimento de espiga a dose de $180 \mathrm{~kg} \mathrm{ha}^{-1}$ promoveu maior resultado para essas características, seguido pela dose de 120, 60 e $0 \mathrm{~kg} \mathrm{ha}^{-1}$ em ambas as safras de milho, sendo que para o número de grãos por fileira, na safra 2004/2005 a resposta foi cúbica e na safra seguinte quadrática (Figura 2B), concordando com Sangoi et al. (2001) que obtiveram ajustes lineares e quadráticos quando estudaram o efeito de doses de $\mathrm{N}$ e diferentes híbridos. Para Carvalho et al. (2012), os valores médios de número de grão por espiga houve diferencia significativa entre as doses de nitrogênio aplicadas, sendo que, a aplicação de $80 \mathrm{~kg} \mathrm{ha}^{1}$ não diferiu da aplicação de $160 \mathrm{~kg} \mathrm{ha}$.

Para o comprimento de espiga a dose de 180 $\mathrm{kg} \mathrm{ha}^{-1}$ promoveu o maior resultado e o ajuste foi quadrático em ambas as safras (Figura 2C), concordando com Fernandes e Buzetti (2005) que estudaram doses de $\mathrm{N}$ na produtividade de seis cultivares de milho.

Quanto ao número de fileiras por espiga o tratamento que não se aplicou $\mathrm{N}$ apresentou o menor resultado diferindo significativamente das demais doses de $\mathrm{N}$, à semelhança dos resultados obtidos por Fernandes, Buzetti e Silva (2004).

No que diz respeito à matéria seca da parte aérea de plantas a aplicação de $\mathrm{N}$ foi significativa, com a dose de $180 \mathrm{~kg} \mathrm{ha}^{-1}$ promovendo a maior quantidade de massa seca seguida pelas doses de 120,60 e 0 $\mathrm{kg} \mathrm{ha}^{-1}$ em ambas as safras de milho, o mesmo ocorrendo com Araújo, Ferreira e Cruz (2003) e Fernandes (2006) que obtiveram maior produção de matéria seca com a maior dose de $\mathrm{N}$ aplicada. $\mathrm{O}$ ajuste dos resultados foi quadrático para as duas safras de milho quanto à produção de massa seca (Figura 2D). Silva et al. (2002) estudando os efeitos de doses de calcário e de $\mathrm{N}$ no milho, verificaram um ajuste quadrático para a produção de matéria seca da parte aérea em relação às doses de $\mathrm{N}$. 
Figura 2. Regressões para características agronômicas do milho nas safras 2004/2005 e 2005/2006 em função das doses de N. A) altura de plantas; B) número de grãos/fileira; C) comprimento de espiga; D) MS; E) massa de 100 grãos; F) rendimento de grãos.

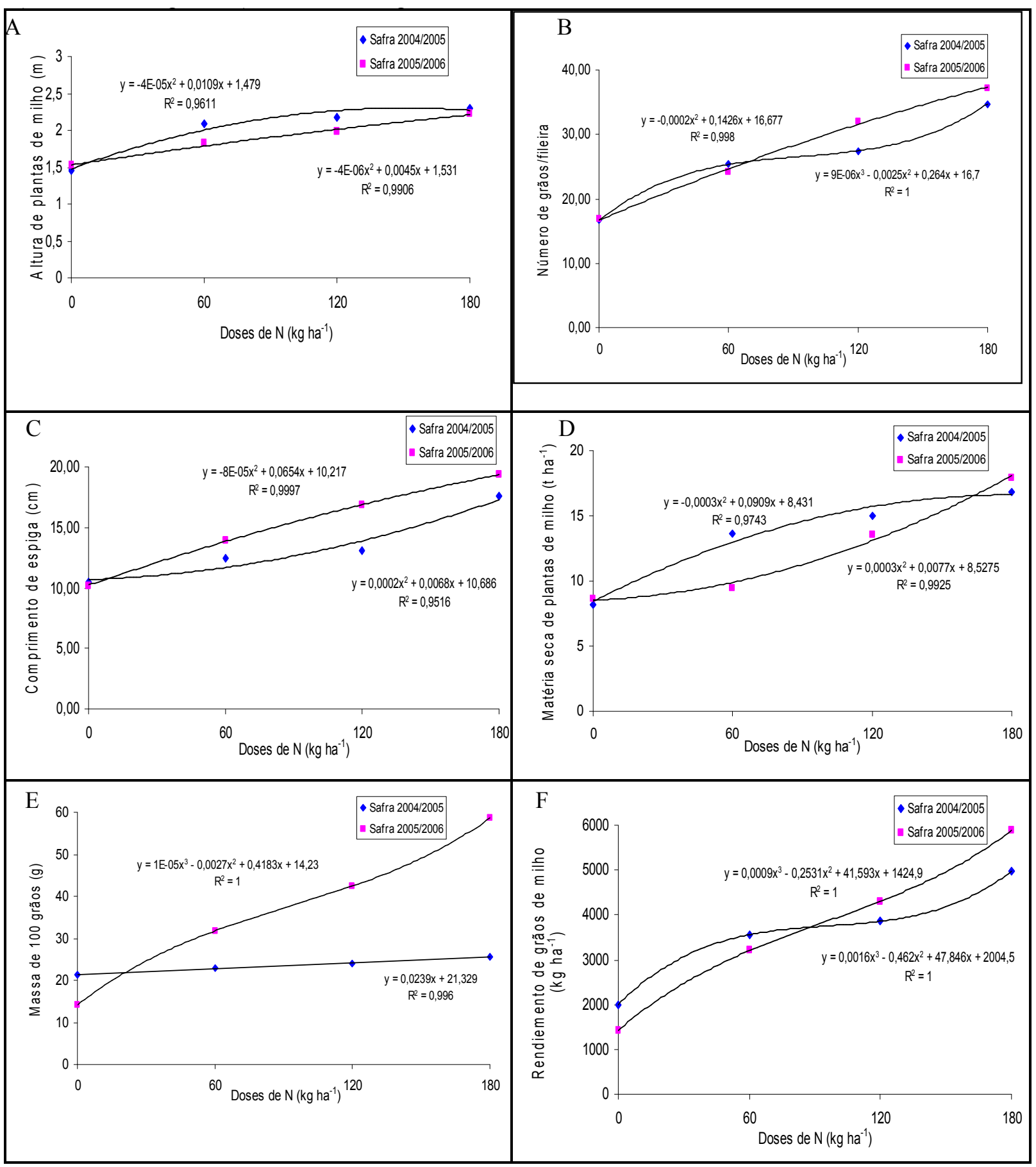

Fonte: Elaboração dos autores. 
Quando se comparam as duas safras, percebe-se que a safra 2004/2005 produziu menor quantidade de matéria seca por planta de milho. De acordo com Argenta et al. (2001), a menor produção de matéria seca por planta de milho em sucessão à aveia preta, pode ser atribuída ao fato de que a adição dos resíduos culturais da cobertura de inverno favoreceu a imobilização de $\mathrm{N}$ pelos microorganismos.

Os resultados obtidos para massa de 100 grãos mostram que para ambas as safras de milho a dose de $180 \mathrm{~kg} \mathrm{ha}^{-1}$ proporcionou maior peso de grãos, seguida pelas doses de 120,60 e $0 \mathrm{~kg} \mathrm{ha}^{-1}$, sendo que na safra 2004/2005, os dados se ajustaram a uma função linear (Figura 2E), à semelhança dos resultados de Fernandes e Buzetti (2005), e na segunda safra, os dados ajustaram-se a uma função cúbica. Verifica-se ainda que, os resultados obtidos para a primeira safra foram menores do que os observados na segunda safra, cuja precipitação foi bem distribuída ao longo de todo o ciclo da cultura. A safra 2004/2005, embora tenha apresentado rendimento satisfatório de grãos, apresentou deficiência no enchimento de grãos. Segundo Pandey, Maranvile e Admou (2000), o período reprodutivo é o período considerado crítico, sendo muito e afetado por condições de falta de água, refletindo assim no rendimento de grãos.

Podem-se relacionar os resultados de rendimento aos de massa de 100 grãos, o qual aumentou com a dose de $\mathrm{N}$ aplicada em ambas as safras com um efeito cúbico das doses (Figura 2F).

Segundo Bortolini et al. (2001) o rendimento de grãos depende dos componentes, número de espigas por planta, número de grãos por espiga e massa de 1000 grãos. Araújo, Ferreira e Cruz (2003), estudando os efeitos da adubação nitrogenada na cultura do milho, também observaram os mesmos resultados obtidos nesta pesquisa quanto ao rendimento de grãos.
Fernandes e Libardi (2012) estudando a distribuição de $\mathrm{N}$ do sulfato de amônio (15N) no sistema solo-planta, em uma sucessão de culturas, sob sistema plantio direto também verificou diferença quanto ao rendimento de grãos, quanto variaram a dose de N. Vale ainda lembrar que, as médias dos tratamentos referentes ao rendimento de grãos nas safras 2004/2005 (3,6 t ha $\left.{ }^{-1}\right)$ e 2005/2006 $\left(3,7 \mathrm{t} \mathrm{ha}^{-1}\right)$ foram equivalentes às médias do Estado de São Paulo, ou seja, 3,7 e 4,0 t ha ${ }^{-1}$, nas respectivas safras (FNP, 2007).

Os resultados de matéria seca das plantas de cobertura de inverno forma significativos para as doses aplicadas e os ajustes estão representados na Figura 3. A resposta da aveia preta às doses de $\mathrm{N}$ foi significativa com a dose de $180 \mathrm{~kg} \mathrm{ha}^{-1}$ proporcionando maior resultado, seguida pelas doses de 120, 60 e $0 \mathrm{~kg} \mathrm{ha}^{-1}$. Entretanto, a quantidade de matéria seca produzida foi considerada baixa (média de $3143 \mathrm{~kg} \mathrm{ha}^{-1}$ ) em todas as doses de $\mathrm{N}$ aplicadas, devido ao plantio tardio, quando comparada com os resultados obtidos por outros autores como Bortolini et al. (2001) e Mai et al. (2003) em experimentos no sul do Brasil, os quais obtiveram 6500, 5700 e 7185 $\mathrm{kg} \mathrm{ha}^{-1}$, respectivamente.

O mesmo comportamento foi observado para o tremoço branco, o qual foi cultivado antes da $2^{\mathrm{a}}$ safra de milho e, este também produziu baixa quantidade de matéria seca (média de $2623 \mathrm{~kg} \mathrm{ha}^{-1}$ ) em relação aos resultados obtidos por Kanthack et al. (1991) que obtiveram $3200 \mathrm{~kg} \mathrm{ha}^{-1}$, não sendo eficiente na formação de palhada devido principalmente à alta taxa de decomposição de seus resíduos (Da ROS; AITA, 1996), deixando o solo desprotegido muito rapidamente. Baixa produção de matéria seca implica em pouca palhada sobre o solo, podendo proporcionar, assim, altas taxas de densidade de fluxo de água no solo. Ainda, observou-se um ajuste em uma curva de regressão cúbica para ambas as plantas de cobertura (Figura 3). 
Figura 3. Regressões para matéria seca das plantas de cobertura de inverno em função das doses de N.

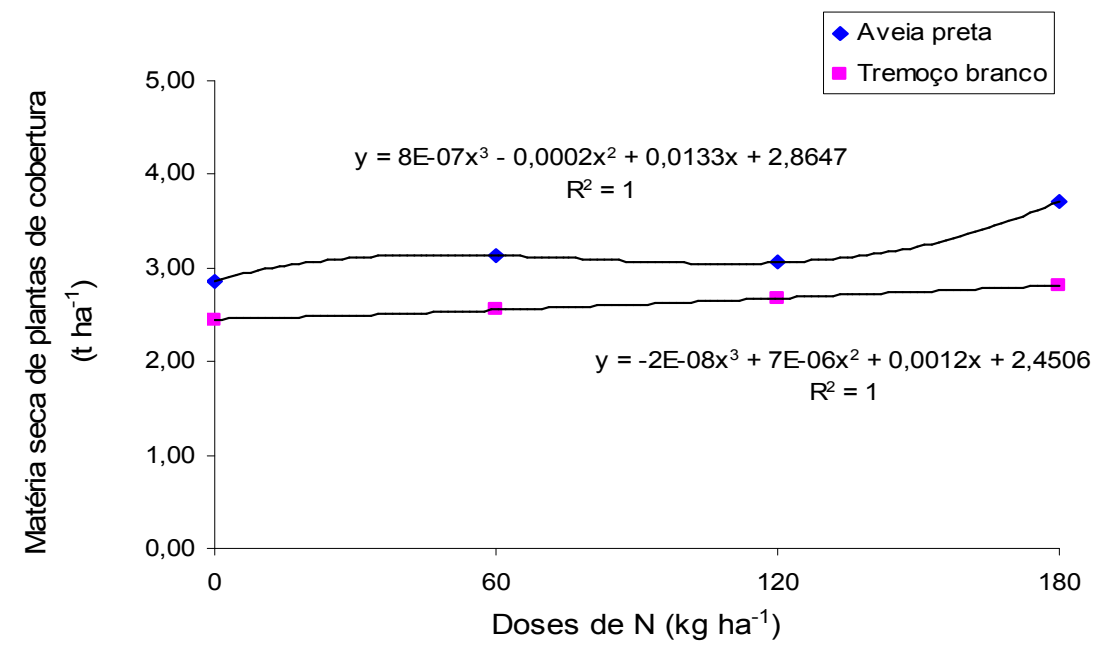

Fonte: Elaboração dos autores.

\section{Conclusões}

As propriedades físicas do solo apresentam tendências de mudança, principalmente no que se refere à macro e microporosidade do solo, pelo aumento e redução, respectivamente, condicionadas pela alteração estrutural do solo. Entretanto, estas mudanças ocorrem paulatinamente, com o tempo e com a aplicação de N, sendo interessante um estudo em longo prazo no SPD, para se obter resultados mais significativos e conclusivos quanto a essa prática de manejo na região.

Os resultados mostraram que, a resposta do rendimento de grãos depende das doses de $\mathrm{N}$ aplicadas, assim como do número de grãos por fileira, tamanho de espiga e massa de 100 grãos de milho.

\section{Referências}

AMADO, T. J. C.; MIELNICZUK, J.; AITA, C. Recomendação de adubação nitrogenada para o milho no RS e SC adaptada ao uso de culturas de cobertura do solo, sob sistema plantio direto. Revista Brasileira Ciência do Solo, Viçosa, v. 26, n. 1, p.241-248, 2002.
ARAÚJO, L. A. N.; FERREIRA, M. E.; CRUZ, M. C. P. Adubação nitrogenada para milho. In: CONGRESSO BRASILEIRO DE CIÊNCIA DO SOLO, 29., 2003, Ribeirão Preto. Resumos expandidos... Ribeirão Preto:UNESP, 2003. 1 CD-ROM.

ARGENTA, G.; SILVA, P. R. F.; FLECK, N. G.; BORTOLINI, C. G.; NEVES, R.; AGOSTINETO, D. Efeitos do manejo mecânico e químico da aveia-preta no milho em sucessão e no controle do capim-papuã. Pesquisa Agropecuária Brasileira, Brasília, v. 36, n. 9, p. 851-860, jun. 2001.

BORTOLINI, C. G.; SILVA, P. R. F.; ARGENTA, G.; FORSTHOFFER, E. L. Rendimento de grãos de milho cultivado após aveia preta em resposta à adubação nitrogenada e regime hídrico. Pesquisa Agropecuária Brasileira, Brasília, v. 36, n. 9, p. 1101-1106, set. 2001.

CARTER, M. R. Evaluation of shallow tillage for spring cereals on a fine sandy loam. II. Soil physical, chemical and biological properties. Soil and Tillage Research, Amsterdam, v. 21, n. 1, p. 37-52, oct. 1991.

CARVALHO, M. A. C.; JUSTEN, P. R.; RIBEIRO, E. D.; ROCHA, V. F. Adubação verde e nitrogenada na cultura do milho. In. CONGRESSO NACIONAL DE MILHO E SORGO, 29., Águas de Lindóia, 2012. Anais... Águas de Lindóia: Embrapa Milho e Sorgo, 2012. CD-ROM.

CASTRO, O. M. de. Compactação do solo em plantio direto. In: FANCELLI, A. L. (Coord.). Plantio direto no Estado de São Paulo. Piracicaba: FEALQ/ESALQ, 1989. p. 129-139. 
COMISSÃO DE FERTILIDADE DO SOLO - CFS-SC/ RS. Recomendações de adubação e de calagem para os Estados do Rio Grande do Sul e de Santa Catarina. Passo Fundo: SBCS- Núcleo Regional Sul, 1995. 224 p.

CORREA, J. C. Efeito de métodos de cultivo em algumas propriedades físicas de um Latossolo Amarelo muito argiloso do Estado do Amazonas. Pesquisa Agropecuária Brasileira, Brasília, v. 20, n. 11, p. 1317-1322, nov. 1985.

COSTA, N. R.; ANDREOTTI, M.; GAMEIRO, R. A.; PARIZ, C. M.; BUZETTI, S.; LOPES, K S. M. Adubação nitrogenada no consórcio de milho com duas espécies de braquiária em sistema plantio direto. Pesquisa Agropecuária Brasileira, Brasília, v.47, n. 9, p. 10381047, 2012.

DA ROS, A. O.; AITA, C. Efeito de espécies de inverno na cobertura do solo e fornecimento de nitrogênio ao milho em plantio direto. Revista Brasileira de Ciência do Solo, Campinas, v. 20, n. 1, p. 135-140, maio/ago. 1996.

DAM, R. F.; MEHDI, B. B.; BURGESS, M. S. E.; MANDRAMOOTOO, C. A.; MEHUYS, G. R.; CALLUM, I. R. Soil bulk density and crop yield under eleven consecutive years of corn with different tillage and residue practices in a sandy loam soil in central Canada. Soil and Tillage Research, Amsterdam, v. 84, n. 1, p. 41-53, nov. 2005.

EMPRESA BRASILEIRA DE PESQUISA AGROPECUÁRIA - EMBRAPA. Centro nacional de pesquisa de solos. Manual de métodos de análise de solo. 2. ed. Rio de Janeiro: EMBRAPA/CNPS, 1997. 212 p.

Centro Nacional de Pesquisa de Solos. Sistema brasileiro de classificação de solos. Rio de Janeiro: EMBRAPA, 1999. 412 p.

FERNANDES, F. C. S.; BUZETTI, S.; SILVA, M. M. Influência de diferentes níveis e épocas de aplicação de nitrogênio na cultura do milho, na região de Ilha Solteira/ SP. Revista Científica Eletrônica de Agronomia, Garça, v. 1, n. 6, p. 1-5, 2004.

FERNANDES, F. C. S. Dinâmica do nitrogênio na cultura do milho (Zea mays L.), em cultivo sucessivo com aveia preta (Avena strigosa), sob implantação do sistema plantio direto. 2006. Tese (Doutorado em Solos e Nutrição de Plantas) - Universidade de São Paulo, Piracicaba.

FERNANDES, F. C. S.; LIBARDI, P. L. Distribuição do Nitrogênio do Sulfato de Amônio (15N) no sistema soloplanta, em uma sucessão de culturas, sob sistema plantio direto. Revista Brasileira de Ciência do Solo, Viçosa, v. 36, n. 3, p. 885-893, 2012.
FERNANDES, F. C. S.; BUZETTI, S. Efeito de níveis de nitrogênio na produtividade de seis cultivaresde milho. Revista Científica Eletrônica de Agronomia, Garça v. 4, n. 7, p. 1-5, 2005.

FIDALSKI, J.; TORMENA, C. A.; CECATO, U.; BARBERO, L. M.; LUGÃO, S. M. B. C.; COSTA, M. A. T. Qualidade física do solo em pastagem adubada e sob pastejo contínuo. Pesquisa Agropecuária Brasileira, Brasília, v. 43, n. 11, p. 1583-1590, 2008.

FNP CONSULTORIA \& COMÉRCIO. Agrianual 2007. Anuário da agricultura brasileira. São Paulo, 2007. 516 p.

GRABLE, A. R.; SIEMER, E. F. Effects of bulk density, aggregate size and soil water suction on oxygen diffusion, redox potential and elongation of corn roots. Soil Science Society of American Journal, Madison, v. 32, n. 1, p. 180186, 1968.

HAITI, K. M.; SWARUP, A.; DWIVEDI, A. K.; MISRA, A. K.; BANDYOPADHYAY, K. K. Changes in soil physical properties and organic carbon status at the topsoil horizon of a vertisol of central India after 28 years of continuous cropping, fertilization and manuring. Agriculture, Ecosystems and Environment, Amsterdam, v. 119, n. 1, p. 127-140, feb. 2007.

KANTHACK, R. A. D.; MASCARENHAS, H. A. A.; CASTRO, O. M. de; TANAKA, R. T. Nitrogênio aplicado em cobertura no milho após tremoço. Pesquisa Agropecuária Brasileira, Brasília, v. 26, n. 1, p. 99-104, jan. 1991.

KUSHWAHA, C. P.; SINGH, K. P.; TRIPATHI, S. $\mathrm{K}$. Soil organic matter and water-stable aggregates under different tillage and residue conditions in a tropical dryland agroecosystem. Applied Soil Ecology, Amsterdam, v. 16, n. 1, p. 229-241, mar. 2001.

LANGE, A. Palhada e nitrogênio afetando propriedades do solo e rendimento de milho em sistema plantio direto no cerrado. 2002. Dissertação (Mestrado em Agronomia) - Universidade Federal de Lavras, Lavras.

LANZANOVA, M. E.; NICOLOSO, R. S.; LOVATO, T.; ELTZ, F. L. F.; AMADO, T. J. C.; REINERT, D. J. Atributos físicos do solo em sistema de integração lavoura-pecuária sob plantio direto. Revista Brasileira de Ciência do Solo, Viçosa, MG, v. 31, p. 1131-1140, 2007.

LOVATO, T.; MIELNICZUK, J.; BAYER, C.; VEZZANI, C. Adição de carbono e nitrogênio e sua relação com os estoques no solo e com o rendimento do milho em sistemas de manejo. Revista Brasileira de Ciência do Solo, Viçosa, MG, v. 28, p. 175-187, 2004. 
MAI, M. E. M.; CERETTA, C. A.; BASSO, C. J.; SILVEIRA, M. J.; PAVINATO, A.; PAVINATO, P. S. Manejo da adubação nitrogenada na sucessão aveia-preta/ milho no sistema plantio direto. Pesquisa Agropecuária Brasileira, Brasília, v. 38, n. 1, p. 125-131, jan. 2003.

MARINARI, S.; MASCIANDARO, G.; CECCANTI, B.; GREGO, S. Influence of organic and mineral fertilisers on soil biological and physical properties. Bioresource Technology, Essex, v. 72, n. 1, p. 9-17, mar. 2000.

MUNKHOLM, L. J.; SCHJØNNING, P.; RASMUSSEN, K. J.; TANDERUP, K. Spatial and temporal effects of direct drilling on soil structure in the seedling environment. Soil and Tillage Research, Amsterdam, v. 71, n. 1, p. 163-173, june 2003.

PANDEY, R. K.; MARANVILE, J. W.; ADMOU, A. Deficit irrigation and nitrogen effects on maize in a Sahelian enviroment I. Grain yield and yield components. Agricultural Water Management, Amsterdam, v. 46, n. 1, p. 1-13, nov. 2000.

RAIJ, B.; CANTARELlA, H.; QUAGGIO, J. A.; FURLANI, A. M. Recomendações de adubação e calagem para o Estado de São Paulo. Campinas: Instituto Agronômico, 1997. 285 p. (Boletim técnico, 100).

SANGOI, L.; ENDER, M.; GUIDOLIN, A. F.; ALMEIDA, M. L.; KONFLANZ, V. A. Nitrogen fertilization impacto $\mathrm{n}$ agronomic traits of maize hybrids released at different decades. Pesquisa Agropecuária Brasileira, Brasília, v. 36, n. 7, p. 757-764, maio 2001.

SARMENTO, P.; RODRIGUES, L. R. de A.; CRUZ, M. C. P. da; LUGÃO, S. M. B.; CAMPOS, F. P. de; CENTURION, J. F.; FERREIRA, M. E. Atributos químicos e físicos de um Argissolo cultivado com Panicum maximum Jacq. cv.IPR-86 Milênio, sob lotação rotacionada e adubado com nitrogênio. Revista Brasileira de Ciência do Solo, Viçosa, v. 32, n. 1, p. 183-193, 2008.
SECCO, D.; DA ROS, C. O.; SECCO, J. K.; FIORIN, J. E. Atributos físicos e produtividade de culturas em um Latossolo Vermelho argiloso sob diferentes sistemas de manejo. Revista Brasileira de Ciência do Solo, Viçosa, v. 29, n. 3, p. 407-414. 2005.

SILVA, A. P.; NADLER, A.; KAY, B. D. Factors contributing to temporal stability in spatial patterns of water content in the tillage zone. Soil and Tillage Research, Amsterdam, v. 58, n. 1, p. 207-218, mar. 2001.

SILVA, D. A.; VITORINO, A. C.; SOUZA, L. C.; GONÇAlVES, M. C.; ROSCOE, R. Culturas antecessoras e adubação nitrogenada na cultura do milho, em sistema plantio direto. Revista Brasileira de Milho e Sorgo, Sete Lagoas, v. 5, n. 1, p. 75-88, 2006.

SOUZA, Z. M.; ALVES, M. C. Propriedades físicas e teor de matéria orgânica em um Latossolo Vermelho de cerrado sob diferentes usos e manejos. Acta Scientiarum, Maringá, v. 25, n. 1, p. 27-34, 2003.

STONE, L. F.; SILVEIRA, P. M. Efeitos do sistema de preparo e da rotação de culturas na porosidade e densidade do solo. Revista Brasileira de Ciência do Solo, Viçosa, v. 25, n. 2, p. 395-401, maio/jun. 2001.

TOZETTI, A. D.; BILLIA, R. C.; SILVA, C.; CERVIGNI, G.; GOMES, O. M. T. Avaliação de progênies de milho na presença e ausência de adubo. Revista Científica Eletrônica de Agronomia, Garça, v. 6, n. 5, p. 6-10, 2004.

VIEIRA, M. J.; MUZILLI, O. Características físicas de um Latossolo Vermelho-Escuro sob diferentes sistemas de manejo. Pesquisa Agropecuária Brasileira, Brasília, v. 19, n. 7, p. 873-882, jul. 1984.

VOORHEES, W. B.; LINDSTROM, M. J. Long-term effects of tillage method on soil tilth independent of wheel traffic compaction. Soil Science Society of America Journal, Madison, v. 48, n. 1, p. 152-156, 1984. 
